\title{
Severe, Persistent and Fatal Delirium in Psychogeriatric Patients Admitted to a Psychiatric Hospital
}

\author{
Ingrid S. Jans $^{\mathrm{a}}$ Letty Oudewortel ${ }^{\mathrm{a}}$ Paulien M. Brandt ${ }^{\mathrm{a}}$ \\ Willem A. van Goola, b \\ a Psychogeriatric Observation Unit, Institution for Mental Health Care 'Dijk en Duin',

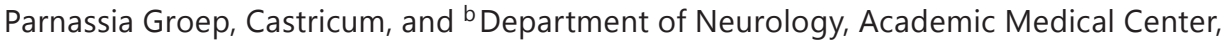 \\ University of Amsterdam, Amsterdam, The Netherlands
}

\author{
Key Words \\ Severe delirium · Persistent delirium · Hallucinations · Delusions · Alzheimer's disease · \\ Dementia $\cdot$ Dementia with Lewy bodies $\cdot$ Treatment $\cdot$ Neuropathology
}

\section{Abstract}

Background/Aims: Although delirium is generally regarded as a transient syndrome, persistence of delirium in patients with cognitive impairment - even with fatal outcome - has been reported as well. This study aims to describe the clinical features and neuropathological correlates of this type of delirium. Methods: Inclusion criteria for this case series were: (1) severe persistent delirium until death, (2) history of cognitive decline and (3) consent for brain autopsy. Medical records were examined in combination with collected clinical data and neuropathological findings. Result: In 15 patients, all living at home before admission, episodes with delirium lasted for 4.2 months on average. No distinct medical causes of persistent delirium could be identified. Pathological diagnoses included Alzheimer's disease and dementia with Lewy bodies as well as single cases of Creutzfeldt-Jakob disease and progressive supranuclear palsy. Conclusion: Severe, persistent and fatal delirium in patients with cognitive impairment can occur relatively early in the disease trajectory and is associated with diverse neuropathologies. 


\section{Introduction}

The multifactorial model of the cause of delirium, as a fluctuating disorder of attention and cognition, recognizes a complex interplay between predisposing and precipitating factors [1]. Cognitive impairment of different degrees of severity, including clinically manifest dementia, is recognized as one of the most important predisposing factors. Precipitating factors include many acute and chronic (medical) conditions such as polypharmacy, use of psychoactive drugs, physical restraints, abnormality in laboratory measurements and infection. As these factors are amenable to treatment, delirium is generally regarded as a transient syndrome that tends to respond well to either treatment of an underlying medical condition or to symptomatic treatment in the majority of patients. Indeed, studies in general hospital populations usually report average delirium durations in the range of 3-5 days [2-4], but persistence of delirium up to 6 months after its onset has been reported as well [5]. More severe delirium and failure to improve are associated with high mortality in nursing home residents [6]. Comorbid cognitive impairment and clinically manifest dementia have been identified to be associated with episodes of prolonged delirium [5], whereas delirium itself increases the risk of incident dementia [7, 8]. Geriatric syndrome complications, e.g. falls, fecal impaction, pressure ulcers, urinary retention, malnutrition, pain and aspiration, may play a role in a vicious spiral leading to new complications and thus persistence of delirium, with long-term decline and death as possible outcomes $[9,10]$.

These observations suggest a complex interplay between neurodegenerative disease as a pivotal predisposing factor in delirium on the one hand and the spectrum of medical conditions precipitating delirium on the other. However, the specific clinical characteristics and the associated neuropathology in patients suffering from extended periods of delirium remain largely unknown as, to our knowledge, there are no (autopsy) studies performed on this topic. In the present case series of consecutive patients with severe and longstanding delirium with fatal outcome, we describe the variations in clinical features of this form of delirium and the spectrum of its neuropathological correlates.

\section{Methods}

\section{Patients and Setting}

From 2008 onwards, consecutive patients were selected among admissions to a closed psychogeriatric unit of a general psychiatric hospital. Patients admitted to this unit suffer from cognitive disorders, severe behavioral problems and associated loss of capacity for selfcontrol. The associated increase in the risk of harm in these subjects precludes safe therapeutic management and treatment in a nursing home or a general open ward of the psychiatric hospital. Patients are referred by medical specialists.

Patients were included in this study if they fulfilled the following three criteria: (1) severe delirium, observed by trained nurses using the Delirium Observation Screening Scale (DOS) [11] and diagnosed by trained specialist doctors in geriatric medicine according to DSM-IV criteria [12], persisting until death; (2) a documented history of cognitive impairment or a (differential) diagnosis of a neurodegenerative disease causing dementia, classified according to DSM-IV criteria, and (3) consent for brain autopsy, as obtained from the legal representative.

On the unit, from 2011 onwards, coercive nursing interventions were banned (e.g. restraints such as side rails, limb restraints or lap trays). To reduce the risk of falling, the multidisciplinary team applied preventive strategies in individualized care plans. The nursing staff comprised only well-trained professionals with experience in caring for elderly patients with severe behavioral abnormalities. Two specialists in geriatric medicine were responsible 
Jans et al.: Severe, Persistent and Fatal Delirium in Psychogeriatric Patients Admitted to a Psychiatric Hospital

for medical care. All individual treatment and care plans conformed to current Dutch multidisciplinary guidelines for delirium and dementia $[13,14]$. Possible causes of delirium were meticulously investigated (infectious, neurologic or metabolic disorders, use of multiple drugs, or urinary retention and fecal impaction) and treated if indicated. Weekly, a neurologist, a psychiatrist and a psychologist were available for consultation. Family members were supported by the team. All regulations were followed with respect to privacy, and informed consent was obtained from a legal representative for the autopsy, including an examination of the brain and use of the data for publication. According to Dutch law, no special permission or ethics approval was required.

\section{Analyses}

All medical records, including those of ambulatory psychogeriatric services, general practitioners over previous years, information from other medical specialists and information from caregivers, were meticulously examined to determine the age at onset of the very first symptoms of cognitive impairment, the dementia diagnosis made according DSM-IV criteria [12], indicators of severity of cognitive impairment such as the Mini-Mental Status Examination (MMSE) [15] and neuropsychological testing, the nature of presenting symptoms, the reason for admission and the duration of delirium. The records were also examined for concurrent psychiatric or medical conditions and the use of psychotropic and other medications. The Charlson comorbidity index was used to characterize the burden of medical conditions at admission [16].

Postmortem examinations were performed within $24 \mathrm{~h}$ after death according to professional standards. After fixation, the neuropathologist examined the brains and first identified macroscopically visible cerebral infarcts and lacunae as well as the pigmentation of the substantia nigra and the locus coeruleus. Samples for microscopy were obtained from the neocortex, hippocampus, midbrain and brainstem. Infarcts were scored as present or absent. Standardized protocols and scoring were followed for quantifying Alzheimer-type pathology, neurofibrillary changes and amyloid deposits as well as $\alpha$-synucleinopathy, all according to Braak and colleagues $[17,18]$.

To study if an episode of delirium might have had an accelerating effect on disease progression in patients with comorbid neurodegenerative disease, we performed the following explorative analysis. Patients with a neuropathological diagnosis of either Alzheimer's disease (AD), dementia with Lewy bodies (DLB) or AD/DLB were included if there was a reliable estimate available from (1) the history of the disease onset, preferably from more than one source, combined with (2) documentation of at least one MMSE score. By subtracting this MMSE score from the maximum of 30 and dividing this figure by the time elapsed between disease onset and the date of the MMSE score, an estimate of the rate of cognitive decline was obtained for the period prior to the onset of delirium [19]. This approximation of the 'rate of prior cognitive decline' allowed calculating an estimate of the MMSE score just before the onset of delirium. Since the onset of delirium and the time of death were also known, we could make a crude approximation of individual trajectories of disease progression, both for the period before the onset of delirium as well as for the episode from delirium onset until death.

\section{Results}

Patient Characteristics and Clinical Features

From 2008 through 2013, consent for brain autopsy was obtained for 15 consecutive patients that fulfilled the criteria of a prior history of cognitive decline and persistent delirium 
Jans et al.: Severe, Persistent and Fatal Delirium in Psychogeriatric Patients Admitted to a Psychiatric Hospital

until death. The patient characteristics are presented in table 1 . The patients' mean age at onset of cognitive and/or neuropsychiatric symptoms was 70.3 years (SD 7.30, range 56-79), and the mean age at death was 75.4 years (SD 5.11, range 68-81).

Before admission, all patients were living at home, some independently and others with some form of supportive care. The average score on the MMSE was 21.0 (SD 4.96, range 13-29) before the onset of delirium. In 3 patients only the referring medical specialists explicitly diagnosed delirium. In the remaining 12 cases, the reasons for referral to the specialized unit were diverse, ranging from aggression or confusion to hallucinations in combination with cognitive disorders.

Study of the medical records on admission identified a diversity of comorbid medical problems. The median score on the Charlson comorbidity index was 3 (range 1-4).

\section{Delirium Characteristics and Medical Treatment}

For an average of 4.2 months (SD 2.82, range 1.5-12), the patients exhibited disturbances in attention and awareness as well as fluctuating cognition day and night. In almost all patients, purposeless fidgeting could be observed, as well as disinhibited and repetitive behavior. Patients suffered from horrific hallucinations, tragic delusions and severe aggressive outbursts. Patients, family members and health professionals experienced this as an immense burden. Four representative case descriptions are provided in table 2 to illustrate the intensity and persistence of delirium and its burden.

The patients were treated according to Dutch multidisciplinary guidelines for delirium and dementia. Review of the medications and standardized laboratory investigations were standard procedures.

In 2 patients, infections and metabolic disturbances were found and successfully treated, without any positive influence on delirium. Throughout the entire clinical episode, special notice, treatment and care were given to geriatric syndrome complications. All patients received expert nursing counseling in addition to intensive drug treatment (table 1). Benzodiazepines were frequently prescribed because of severe anxiety or aggression, despite the equivocal effect of benzodiazepines in delirium [20]. Pneumonia was identified as the primary cause of death in 3 patients. One patient died from compromised (cardio)pulmonary status and 1 from congestive heart failure. In the remaining 10 patients, no single cause of death could be determined; at the end of their life, all patients suffered from exhaustion, dehydration and cachexia.

\section{Neuropathology}

In 1 patient (No. 6), the clinical diagnosis of Creutzfeldt-Jakob disease could be confirmed. In patient No. 4, with an alien limb phenomenon, corticobasal degeneration was suspected, but the neuropathological diagnosis was progressive supranuclear palsy. One patient (No. 5) with neuropathological, confirmed AD also had two small subdural hematomas at autopsy. In the remaining 12 patients, neuropathological examination confirmed a diagnosis of $\mathrm{AD}(\mathrm{n}=$ 7), DLB ( $n=3)$ or mixed AD/DLB $(n=2)$ (table 3). In 2 patients (No. 9 and 12) harboring a significant AD pathology, capillary $\beta$-amyloid deposits were found to spread into the surrounding neuropil in flame-like depositions (dyshoric angiopathy) [21, 22].

\section{Disease Trajectories}

One or more MMSE scores from the period before the onset of delirium were available for 9 of 12 patients with AD and/or DLB neuropathology. Combined with estimates of the time elapsed since first symptoms, this allowed for an approximation of disease progression over time before the onset of delirium. This figure was used to estimate an MMSE score at the time of delirium onset, as illustrated in figure 1. Although these estimates were necessarily 


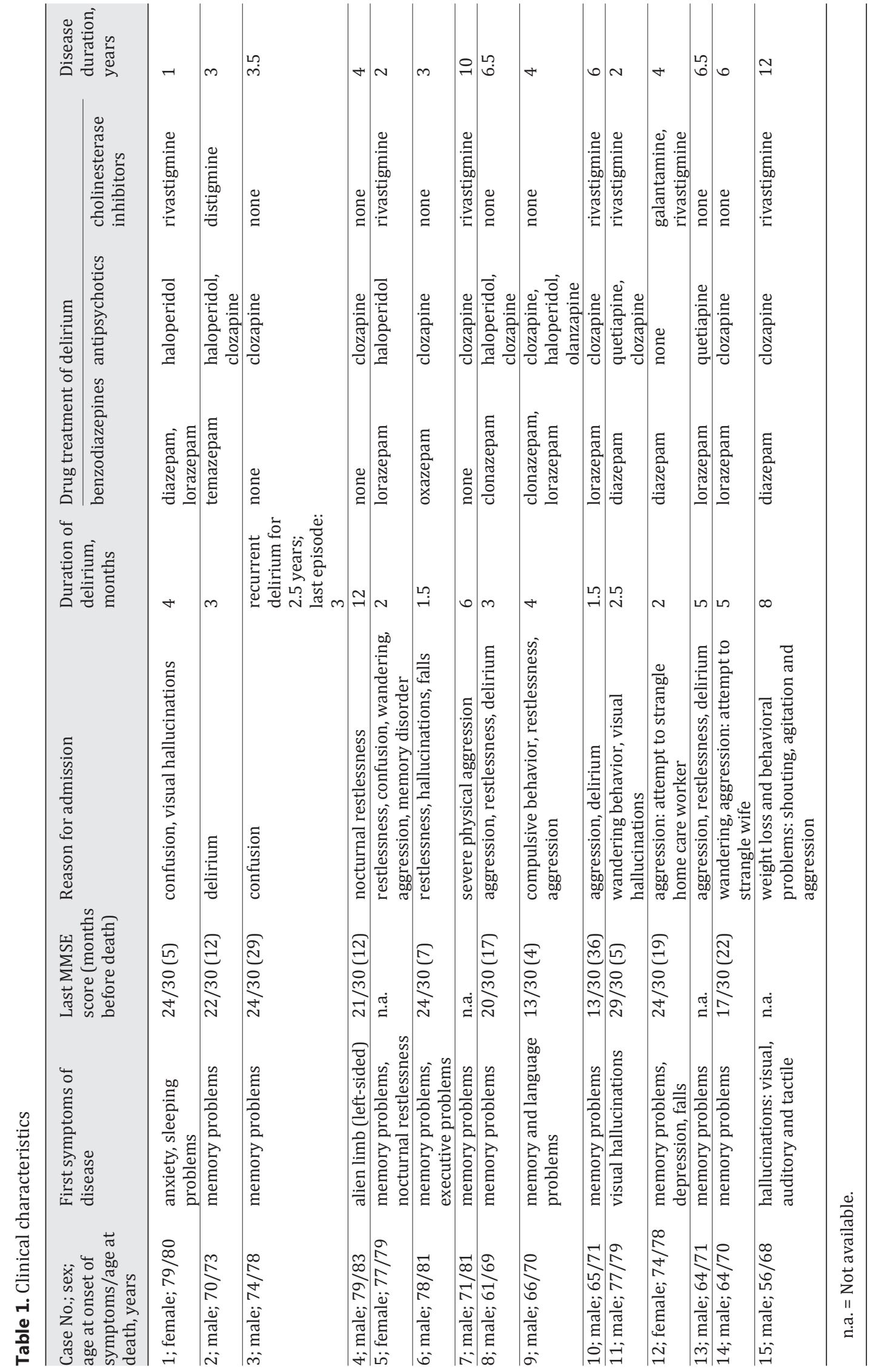


Table 2. Case vignettes

Patient No. 1

At the age of 79 years, this patient reported anxiety and sleeping problems. Her MMSE-score was 24/30 a month before admission. Moments of confusion, anxiety and restlessness became more frequent, especially at night. She developed hallucinations of strangers. Sometimes she crawled on the ground out of fear. She reported double vision, problems with depth perception and word finding. There were fluctuations of cognition, consciousness, agitation, anxiety and panic. She developed epilepsy and tremor. She was at an increased risk of falling and showed purposeless, repetitive behavior, picking at imaginary things and groping. She could not sleep at night, had difficulty swallowing and cried frequently. She was disoriented and had executive problems, and sometimes she did not recognize objects. She developed a staring gaze and reported seeing the burial of a child, wrecked ships and a house on fire. After an episode of delirium of 4 months, she died of cachexia and dehydration at the age of 80 years.

Patient No. 5

After a history of alcoholism, this 77-year-old former nurse started to experience memory problems and nocturnal restlessness. Two years later, she experienced a sudden worsening of functioning: normal episodes alternated with delirious episodes. After a fall, a humerus fracture and subdural hematoma were diagnosed. The fracture was operated and the subdural hematoma was treated conservatively. A rapidly progressive worsening followed, with loss of mobility, rigidity, hallucinations of people and objects, impaired attention, delayed responses, increased distractibility, anxiety, shouting, irritability, restlessness, aggression (kicking and pinching) and shouting. The patient suffered of delirium for 2 months and died of pneumonia at the age of 79 years.

Patient No. 7

At the age of 72 years, this former carpenter reported short-term memory problems, but an examination revealed no cognitive impairments at that time. From the age of 79 years onwards, his cognitive functions declined rapidly, with increasing memory problems and getting lost while shopping. He became agitated, which led to conflicts with his wife and children. Visual hallucinations and paranoid delusions contributed to his anxiety and aggression. Shortly before admission, he threw screwdrivers at his wife and attempted to strangle his daughter, who fled from the house. At admission, he showed severe verbal and physical aggression. He was paranoid and disoriented. He was beating and kicking at doors and windows. He tried to put his fingers in the plug connection. He urinated in rooms and in the sink, attempted to eat cigarettes from ashtrays and grasped at fingers of nurses, trying to put them in his mouth. He crawled on his hands and knees, threw cups, moved and disassembled furniture and the bath, shouted, and undressed and tore his clothes apart while talking to imaginary people. Upon clozapine treatment, he developed an agranulocytosis. After a period of 6 months of delirium, he died of pneumonia and sepsis.

Patient No. 11

At the age of 77 years, with an MMSE score of 29/30, this patient, living alone on a houseboat, developed visual hallucinations: human heads, flowerpots and furniture changing into people, strangers in his house urinating and eating snails, 50 people with musical instruments in swaying willow branches, skaters on the meadow or people with horns playing with electric wires. He was afraid that people would burn his house. He had progressive sleeping problems, became slower and lost interest. He fell regularly and developed a shuffling gait, excessive saliva and stiffness but no clear cognitive disturbances. On haloperidol, and later also on quetiapine, he developed a malignant neuroleptic syndrome. He became increasingly anxious and restless, especially at night, tearing his clothes apart. He experienced being on a boat and seeing people who were shot, and he thought that people were stealing from him, that he drank wine from the pope and that he would be decapitated. The patient suffered from delirium for 2.5 months before he died of cachexia and dehydration at the age of 79 years. 


\begin{tabular}{l|l}
\hline DOI: $10.1159 / 000381847$ & \\
\hline
\end{tabular}

(C) 2015 S. Karger AG, Basel www.karger.com/dee

Jans et al.: Severe, Persistent and Fatal Delirium in Psychogeriatric Patients Admitted to a Psychiatric Hospital

Table 3. Neuropathological characteristics

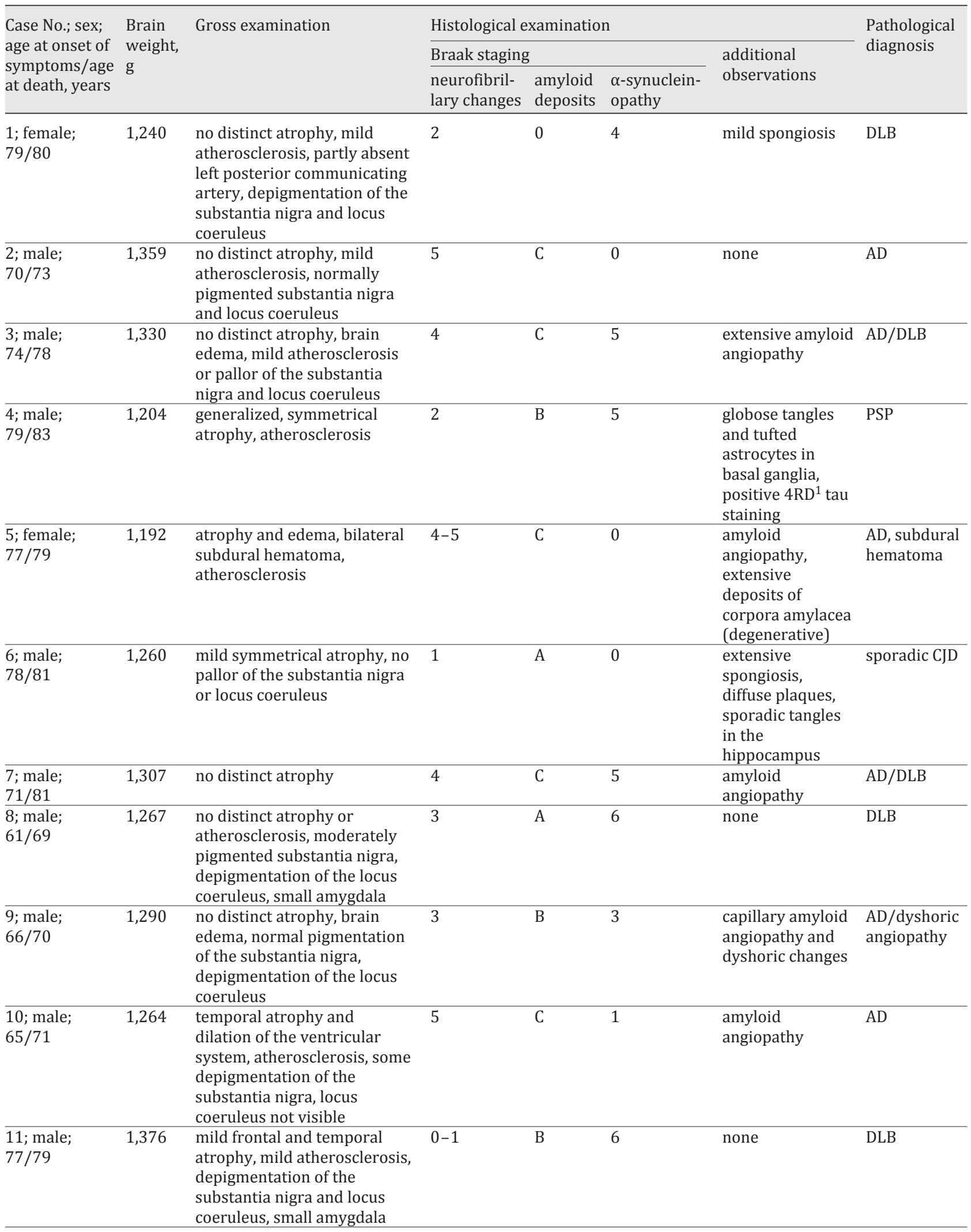


Table 3 (continued)

\begin{tabular}{|c|c|c|c|c|c|c|c|}
\hline \multirow{3}{*}{$\begin{array}{l}\text { Case No.; sex; } \\
\text { age at onset of } \\
\text { symptoms/age } \\
\text { at death, years }\end{array}$} & \multirow{3}{*}{$\begin{array}{l}\text { Brain } \\
\text { weight, } \\
\mathrm{g}\end{array}$} & \multirow[t]{3}{*}{ Gross examination } & \multicolumn{4}{|c|}{ Histological examination } & \multirow{3}{*}{$\begin{array}{l}\text { Pathological } \\
\text { diagnosis }\end{array}$} \\
\hline & & & \multicolumn{3}{|l|}{ Braak staging } & \multirow{2}{*}{$\begin{array}{l}\text { additional } \\
\text { observations }\end{array}$} & \\
\hline & & & $\begin{array}{l}\text { neurofibril- } \\
\text { lary changes }\end{array}$ & $\begin{array}{l}\text { amyloid } \\
\text { deposits }\end{array}$ & $\begin{array}{l}\alpha \text {-synuclein- } \\
\text { opathy }\end{array}$ & & \\
\hline $\begin{array}{l}\text { 12; female; } \\
74 / 78\end{array}$ & 1,459 & $\begin{array}{l}\text { mild frontomedial atrophy, } \\
\text { some ventricular dilation, } \\
\text { atherosclerosis, some } \\
\text { depigmentation of the } \\
\text { substantia nigra, locus } \\
\text { coeruleus not visible }\end{array}$ & 5 & B & 0 & $\begin{array}{l}\text { extensive } \\
\text { capillary amyloid } \\
\text { angiopathy and } \\
\text { dyshoric changes }\end{array}$ & $\begin{array}{l}\text { AD/dyshoric } \\
\text { angiopathy }\end{array}$ \\
\hline $\begin{array}{l}\text { 13; male; } \\
64 / 71\end{array}$ & 1,249 & $\begin{array}{l}\text { moderate frontal and } \\
\text { temporal atrophy, mild } \\
\text { atherosclerosis, some } \\
\text { depigmentation of the } \\
\text { substantia nigra, distinct } \\
\text { depigmentation of the locus } \\
\text { coeruleus, atrophy of the } \\
\text { amygdala }\end{array}$ & 6 & $\mathrm{C}$ & $1-2$ & $\begin{array}{l}\text { signs of hypoxia, } \\
\text { amyloid } \\
\text { angiopathy }\end{array}$ & $\mathrm{AD}$ \\
\hline $\begin{array}{l}\text { 14; male; } \\
64 / 70\end{array}$ & 1,330 & $\begin{array}{l}\text { mild atrophy, mild } \\
\text { atherosclerosis, mild } \\
\text { depigmentation of the } \\
\text { substantia nigra, locus } \\
\text { coeruleus appears normal, } \\
\text { signs of old concussion }\end{array}$ & $5-6$ & $\mathrm{C}$ & $1-2$ & $\begin{array}{l}\text { extensive amyloid } \\
\text { angiopathy, } \\
\text { infarction in the } \\
\text { left hippocampus }\end{array}$ & $\mathrm{AD}$ \\
\hline $\begin{array}{l}\text { 15; male; } \\
56 / 68\end{array}$ & n.a. & $\begin{array}{l}\text { frontal and frontotemporal } \\
\text { atrophy }\end{array}$ & 5 & $\mathrm{C}$ & 1 & $\begin{array}{l}\text { hippocampal } \\
\text { sclerosis, signs of } \\
\text { hypoxia }\end{array}$ & $\mathrm{AD}$ \\
\hline
\end{tabular}

\footnotetext{
${ }^{1}$ Specific antibody for tau proteins containing 4 repeats in the microtubule-binding domain. PSP = Progressive supranuclear palsy; CJD = Creutzfeldt-Jakob disease.
}

crude because of the retrospective nature of the data collection, the overall picture seems to identify a subgroup of patients in whom the delirium was associated with an acceleration of deterioration. In 6 patients (No. 1, 2, 3, 8, 11 and 12) (table 1), either the observed MMSE score shortly before the onset of the fatal delirium or the estimated MMSE score at the onset of delirium was well above 15, and in 3 patients even above 20 (fig. 1).

\section{Discussion}

This case series illustrates that in patients with preexisting cognitive impairments or clinically manifest dementia, delirium can be very severe, persisting for several months and unresponsive to any form of symptomatic treatment and may ultimately lead to death. This form of delirium is associated with immense suffering of patients and an extreme burden to families. Before the onset of delirium, all patients of this series had been living at home, and some had had only relatively mild cognitive impairments. Because of its sudden onset, severity, persistence and ultimate fatal outcome, the families and health professionals experienced the episodes of delirium described here as catastrophic.

In the case of the Creutzfeldt-Jakob disease patient (No. 6), the clinical course with rapidly progressive deterioration is of course not unexpected. In the patients (No. 4 and 5) with progressive supranuclear palsy or comorbid subdural hematomas, factors other than amyloid-, tau- or $\alpha$-synucleinopathy per se may have contributed to the detrimental clinical 


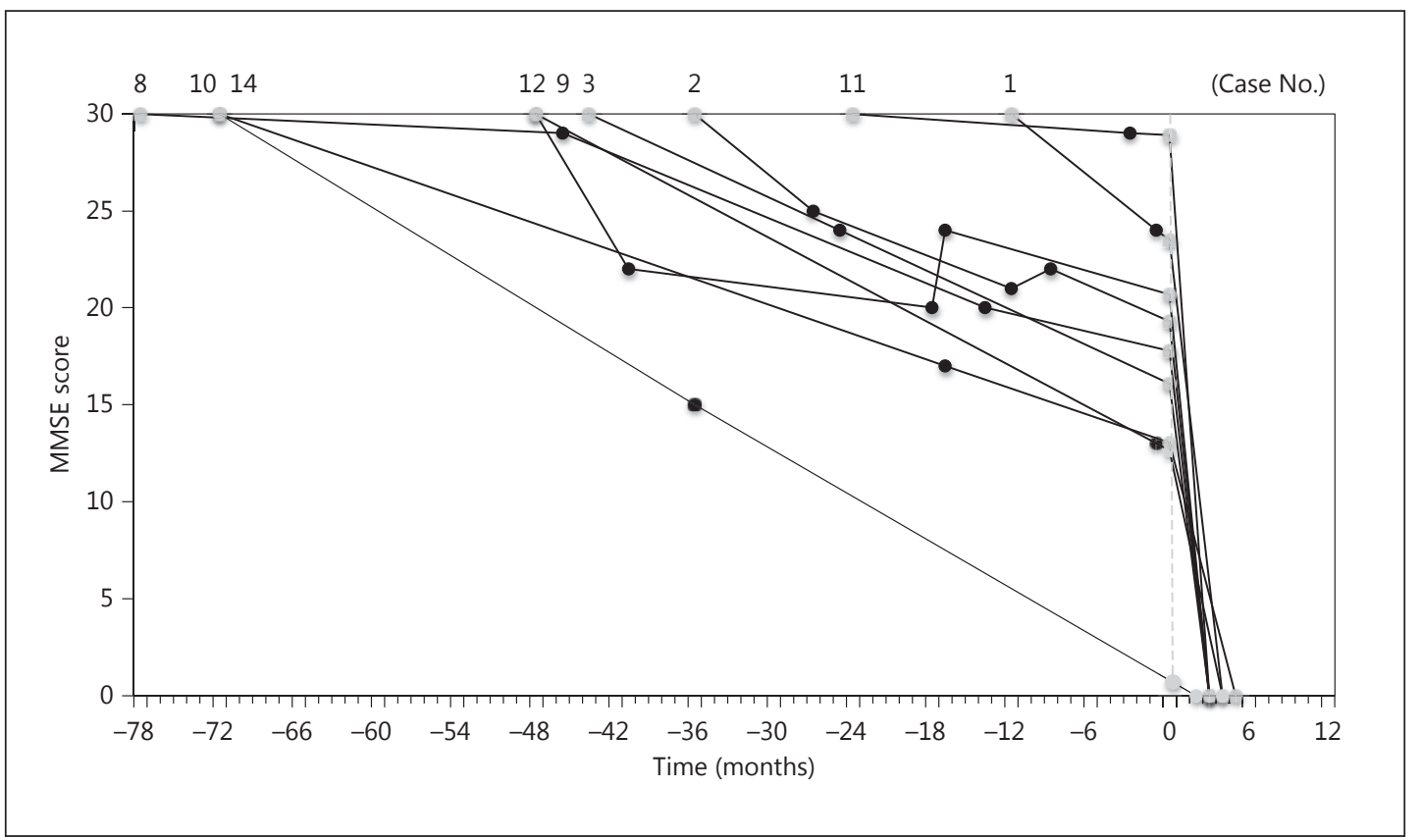

Fig. 1. Reconstruction of disease trajectories in 9 patients (identified by case No. to refer to the tables) for whom at least one MMSE value was available before the onset of delirium, combined with an accurate estimate of the time of onset of symptoms. Based on this estimate and the actual MMSE observations (black dots), imputations (gray dots) were made of the time the MMSE score was maximal and an MMSE score at the time of delirium onset (indicated by a dashed gray line at the '0' point on the x-axis).

course observed. In the group of patients with AD, DLB and AD/DLB, however, the episode of delirium and the clinical course seem to contradict common clinical wisdom on two accounts. First, delirium is generally considered to be a transient state that tends to respond well to correction of precipitating factors and symptomatic treatment. In none of the group of patients with $\mathrm{AD}, \mathrm{DLB}$ and $\mathrm{AD} / \mathrm{DLB}$ did the delirium respond well to any intervention or treatment. Secondly, neurodegenerative diseases are commonly described as gradually progressive from a clinical perspective. In this group of patients, some could be identified with relatively mild predelirium cognitive impairments, and their persistent and intense delirium was associated with rapid clinical deterioration with a fatal outcome (table 1 ; fig. 1). The estimates of the individual trajectories of global cognitive decline (fig. 1) should be interpreted with great caution, because they were based on retrospectively collected data from multiple different sources, and estimates of disease onset, as used for the calculation of the rate of decline, are notoriously inaccurate.

The present data are consistent with the literature suggesting an accelerating effect of delirium on the course of decline in neurodegenerative diseases $[7,9,10]$. Our observations are also consistent with studies suggesting that delirium may not merely be a marker for advanced disease increasing the risk of death, but rather that delirium itself impairs the chances of survival [23]. Severe delirium impairs effective interaction with the environment and the ability to eat and drink, and it often requires symptomatic treatment with drugs with sedative effects, all adding to a vicious cycle of worsening debility and increasing the risks of harm that may ultimately translate into an increased mortality risk.

Dementia is a well-recognized risk factor for delirium [7], and only mild stimuli can trigger a delirious episode in patients with a preexisting neurodegenerative disease [24], whether this 
has led to clinically manifest dementia or not. In the present case series, recognition of delirium before admission was poor. The predominant clinical reason for admission was recognized and labeled as delirium in only 3 of the patients. Failure to recognize delirium in psychogeriatric patients precludes timely and effective intervention, potentially lengthening delirium duration and, thus, aggravating its course [1]. In cases of a catastrophic delirium with severe behavioral disturbances and immense suffering for prolonged periods of time, specialized services may be required. The standard of regular long-term care facilities may not be high enough to cope with these patients. Specialized psychogeriatric services, as described here, preferably embedded in an institute for mental health care, may be best suited to guaranteeing patients and families a therapeutic environment that is as safe and supportive as possible.

It may be hypothesized that the catastrophic delirium described here represents a possible course of clinical symptoms in neurodegenerative diseases. A review of the general literature on delirium, and more specifically on delirium in psychogeriatric populations, suggests that this course of symptoms has not received much attention $[1,5,6]$. To the best of our knowledge, this is the first publication describing neuropathological findings in patients with cognitive impairment and persistent delirium until death. AD was the most common underlying neuropathological disorder. Extensive amyloid angiopathy or capillary amyloid angiopathy was frequently seen. This finding could suggest that an association between persistent delirium and $\mathrm{AD}$ is seen especially in $\mathrm{AD}$ with vascular amyloid deposition. However, the incidence of cerebral amyloid angiopathy increases with age, occurs in 70-100\% of AD patients and is a common finding at autopsy [22].

Consistent with the present findings, a prospective clinical case series did not find specific associations between delirium and any of the conventional neuropathological markers of dementia in a population-based cohort [7]. Future studies focusing on neuropathological markers that may be specifically associated with prolonged and severe delirium (such as, for instance, microglia activation) are warranted $[25,26]$.

A limitation to the present series of consecutive patients is that, because of the small and selected sample, it does not allow for any estimate of the relative frequency of this malignant course of a delirium in clinical populations, let alone in the general population. The patients in this case series were specifically referred to a facility specialized in severe neuropsychiatric problems in psychogeriatric patients. Most probably, the condition described here is relatively rare, although it was observed more frequently at the unit than described, in some patients consent for brain autopsy could not be obtained and other cases did survive an episode of severe and persistent delirium, also associated with rapid clinical deterioration (data not shown).

Another limitation to this study is that during admission, symptoms and changes in clinical state were not systematically monitored by means of standardized screening and observational instruments. This has affected the level of detail that can be provided. Other than the representative case vignettes (table 2 ), we could not provide more objective measurements of the severity of delirium, because there is no validated scale for measuring the severity or burden of delirium in patients with comorbid cognitive impairment or dementia.

In the present case series, we did not identify any significant medical causes of delirium. Precipitating factors contributing to the onset of delirium (such as e.g. a viral infection or any temporary metabolic imbalance) may have gone unnoticed in the period before admission. These hypothetical factors may have disappeared by the time of admission. Moreover, this discussion on the presence or absence of medical factors contributing to delirium alludes to a classic conundrum in neuropsychiatry. Relating to hypothetical endogenous versus exogenous components of delirium, more than a century ago, Karl Bonhoeffer proposed the existence of an 'auto-toxic agent', 'some internal disturbances, maybe those of the cerebral metabolism', as might be the case in a neurodegenerative disease [27]. 
Jans et al.: Severe, Persistent and Fatal Delirium in Psychogeriatric Patients Admitted to a Psychiatric Hospital

One of the strengths of this study is that information about individual disease trajectories from the period before the onset of delirium was available from multiple different sources, including records from ambulatory psychogeriatric services. Moreover, detailed clinical information on the course of disease during admission could be linked to neuropathological data.

\section{Conclusions}

In conclusion, patients suffering from neurodegenerative diseases are subject to the risk of developing severe, persistent and fatal delirium. This form of catastrophic delirium can occur in relatively early clinical stages of cognitive impairment or dementia, and an exploratory analysis suggests that it is associated with rapid clinical deterioration. Its underlying neuropathology is diverse and nonspecific, as determined by routine investigations. It is further associated with an extremely high burden on patients, caregivers and health professionals alike. These factors warrant increased research efforts to uncover specific etiological pathways in order to optimize treatment and thus ultimately to ameliorate the detrimental course of catastrophic delirium or even prevent it entirely.

\section{Acknowledgment}

This work was supported by ZonMW (WAvG, TOP grant No. 40-00812-98-10017).

\section{Disclosure Statement}

The authors declare that they have no competing interests.

\section{References}

1 Inouye SK, Westendorp RG, Saczynski JS: Delirium in elderly people. Lancet 2014;383:911-922.

- 2 Mu JL, Lee A, Joynt GM: Pharmacological agents for the prevention and treatment of delirium in patients undergoing cardiac surgery: systematic review and metaanalysis. Crit Care Med 2015;43:194-204.

- 3 Bellelli G, Mazzola P, Morandi A, Bruni A, Carnevali L, Corsi M, Zatti G, Zambon A, Corrao G, Olofsson B, Gustafson Y, Annoni G: Duration of postoperative delirium is an independent predictor of 6-month mortality in older adults after hip fracture. J Am Geriatr Soc 2014;62:1335-1340.

-4 Al-Qadheeb NS, Balk EM, Fraser GL, Skrobik Y, Riker RR, Kress JP, Whitehead S, Devlin JW: Randomized ICU trials do not demonstrate an association between interventions that reduce delirium duration and short-term mortality: a systematic review and meta-analysis. Crit Care Med 2014;42:1442-1454.

5 Dasgupta M, Hillier LM: Factors associated with prolonged delirium: a systematic review. Int Psychogeriat 2010;22:373-394.

6 Kelly KG, Zisselman M, Cutillo-Schmitter T, Reichard R, Payne D, Denman SJ: Severity and course of delirium in medically hospitalized nursing facility residents. Am J Geriatr Psychiatry 2001;9:72-77.

7 Davis DH, Muniz Terrera G, Keage H, Rahkonen T, Oinas M, Matthews FE, Cunningham C, Polvikoski T, Sulkava $\mathrm{R}$, MacLullich AM, Brayne C: Delirium is a strong risk factor for dementia in the oldest-old: a population-based cohort study. Brain 2012;135:2809-2816.

-8 Witlox J, Eurelings LS, de Jonghe JF, Kalisvaart KJ, Eikelenboom P, van Gool WA: Delirium in elderly patients and the risk of postdischarge mortality, institutionalization, and dementia: a meta-analysis. JAMA 2010;304: 443-451.

-9 Anderson CP, Ngo LH, Marcantonio ER: Complications in postacute care are associated with persistent delirium. J Am Geriatr Soc 2012;60:1122-1127.

10 Gross AL, Jones RN, Habtemariam DA, Fong TG, Tommet D, Quach L, Schmitt E, Yap L, Inouye SK: Delirium and long-term cognitive trajectory among persons with dementia. Arch Intern Med 2012;172:1324-1331. 
11 Schuurmans MJ, Shortridge-Baggett LM, Duursma SA: The Delirium Observation Screening Scale: a screening instrument for delirium. Res Theory Nurs Pract 2003;17:31-50.

12 American Psychiatric Association: Diagnostic and Statistical Manual of Mental Disorders, ed 4 (DSM-IV). Washington, American Psychiatric Association, 1994.

13 Dutch College of Clinical Geriatrics: Richtlijn diagnostiek en medicamenteuze behandeling van dementie. Alphen a/d Rijn, Dutch College of Clinical Geriatrics, 2005.

14 Dutch Psychiatric Association: Richtlijn delier. Amsterdam, Dutch Psychiatric Association, 2004.

15 Folstein MF, Folstein SE, McHugh PR: 'Mini-mental state'. A practical method for grading the cognitive state of patients for the clinician. J Psychiatr Res 1975;12:189-198.

16 Charlson ME, Pompei P, Ales KL, et al: A new method of classifying prognostic comorbidity in longitudinal studies: development and validation. J Chronic Dis 1987;40:373-383.

17 Braak H, Braak E: Staging of Alzheimer-related cortical destruction. Int Psychogeriatr 1997;9(suppl 1):257261.

18 Braak H, Del Tredici K, Bratzke H, Hamm-Clement J, Sandmann-Keil D, Rüb U: Staging of the intracerebral inclusion body pathology associated with idiopathic Parkinson's disease (preclinical and clinical stages). J Neurol 2002;249(suppl 3):III/1-5.

-19 Doody RS, Pavlik V, Massman P, Rountree S, Darby E, Chan W: Predicting progression of Alzheimer's disease. Alzheimers Res Ther 2010;2:2.

-20 National Institute for Health and Clinical Excellence: Delirium: diagnosis, prevention and management. London, National Clinical Guideline Centre, 2010.

21 Attems J: Sporadic cerebral amyloid angiopathy: pathology, clinical implications, and possible pathomechanisms. Acta Neuropathol 2005;110:345-359.

-22 Richard E, Carrano A, Hoozemans JJ, van Horssen J, van Haastert ES, Eurelings LS, de Vries HE, Thal DR, Eikelenboom P, van Gool WA, Rozemuller AJ: Characteristics of dyshoric capillary cerebral amyloid angiopathy. J Neuropathol Exp Neurol 2010;69:1158-1167.

23 Kiely DK, Marcantonio ER, Inouye SK, et al: Persistent delirium predicts greater mortality. J Am Geriatr Soc 2009;57:55-61.

24 Morandi A, Davis D, Fick DM, Turco R, Boustani M, Lucchi E, Guerini F, Morghen S, Torpilliesi T, Gentile S, MacLullich AM, Trabucchi M, Bellelli G: Delirium superimposed on dementia strongly predicts worse outcomes in older rehabilitation inpatients. J Am Med Dir Assoc 2014;15:349-354.

25 Cunningham C, Campion S, Lunnon K, Murray CL, Woods JF, Deacon RM, Rawlins JN, Perry VH: Systemic inflammation induces acute behavioral and cognitive changes and accelerates neurodegenerative disease. Biol Psychiatry 2009;65:304-312.

26 van Gool WA, van de Beek D, Eikelenboom P: Systemic infection and delirium: when cytokines and acetylcholine collide. Lancet 2010;375:773-775.

27 Neumärker KJ: Karl Bonhoeffer and the concept of symptomatic psychoses. Hist Psychiatry 2001;12:213-226. 